\title{
The BAH domain of BAHD1 is a histone H3K27me3 reader
}

\section{Dear Editor,}

Histone recognition by reader modules constitutes a major mechanism for epigenetic regulation (Jenuwein and Allis 2001). BAHD1 (bromo adjacent homology domain containing protein 1) is a vertebrate-specific nuclear protein (Fig. S1) involved in gene silencing by promoting heterochromatin formation. BAHD1 is characteristic with an $\mathrm{N}$-terminal proline-rich region, a nuclear localization signal motif, and a C-terminal bromo adjacent homology (BAH) domain (Fig. 1A). Previous study revealed that BAHD1 could act as a scaffold protein and tether diverse heterochromatinassociated factors including HP1, MBD1, SETDB1, HDAC5, and several transcriptional factors to trigger facultative heterochromatin formation (Bierne, Tham et al. 2009). Consistent with a "repressive" role, BAHD1 binds to CpG-rich P3 promoter region of IGF2 (insulin-like growth factor II) then represses IGF2 and IGF2 antisense transcription via the recruitment of MBD1 and HDAC5 (Bierne, Tham et al. 2009). Intriguingly, BAHD1 is also involved in host-pathogen interplay. For example, at early L. monocytogenes infection state, BAHD1 forms a complex with TRIM28 and HP1 to repress interferon-stimulated genes, including IFNL1, IFNL2, and IFNL3 . At specific infection stages, Listeria secretes a virulence factor, LntA, which could physically interact with BAHD1 to activate interferon (IFN)-stimulated genes (ISGs) (Lebreton, Lakisic et al. 2011). Despite a repressive role of BAHD1, the molecular mechanism underlying BAHD1 heterochromatin targeting remains largely unexplored.

$\mathrm{BAH}$ domain is an evolutionarily conserved motif which is found in several chromatin-associated proteins such as Sir3, ORC1, Rsc2, ZMET2, and DNMT1. BAH is characteristic of a conserved $\beta$-sheet core (typically 9-bladed) flanked with function-specific N-, C-, and $\beta 6-\beta 7$ insertions. Recent structural and functional studies revealed multi-facet roles of BAH domain in chromatin regulation (Yang and $X u$ 2013). For example, in yeast, ORC1 BAH could act as a scaffold to mediate ORC1-Sir1 interaction to form a silencing complex; Sir3 BAH could function as a nucleosome-targeting unit to induce heterochromatin formation; moreover, Rsc2 BAH could bind histone $\mathrm{H} 3$ and its interaction interface is conserved in a subset of Rsc-like BAH domains (Chambers, Pearl et al. 2013). Interestingly, in metazoan species, ORC1 BAH domain has acquired a histone methylation reader activity and recognizes H4K20me2 to prompt DNA replication licensing (Kuo, Song et al. 2012). BAH domains also exist in DNA methyltransferases of mammalian DNMT1 and plant ZMET2. Noteworthily, ZMET2 but not DNMT1 BAH domain displays histone $\mathrm{H} 3 \mathrm{~K} 9 \mathrm{me} 2$ binding activity and thus directly mediates a cross-talk between histone and DNA methylations (Du, Johnson et al. 2015). Previous study showed that deletion of the C-terminal BAH domain interfered with co-localization of BAHD1 with H3K27me3 at nuclear foci in vivo (Bierne, Tham et al. 2009), suggesting a role of $\mathrm{BAH}_{\mathrm{BAHD} 1}$ in histone $\mathrm{H} 3 \mathrm{~K} 27 \mathrm{me} 3$ recognition. In order to test this hypothesis, we recombinantly expressed $\mathrm{BAH}_{\mathrm{BAHD} 1}$ (aa 589-780) with an N-terminal GST tag, and carried out modified histone peptide array screening (Fig. 1B). Many black dots of different intensities were detected in the grid, supporting a histone binding activity of $\mathrm{BAH}_{\mathrm{BAHD} 1 \text {. In-depth data analysis revealed }}$ that all the positive hits can be classified into two major categories: the H3K9me2/3-containing and the H3K27me2/3containing clusters. Among these hits, $\mathrm{H} 3 \mathrm{~K} 27$ me3-containing peptides displayed strongest signal, consistent with a proposed role of $\mathrm{BAH}_{\mathrm{BAHD} 1}$ in $\mathrm{H} 3 \mathrm{~K} 27 \mathrm{me} 3$ recognition.

In order to quantitatively characterize the array data, we performed isothermal titration calorimetry (ITC) under an optimized buffer condition that gives a better melting temperature $\left(\mathrm{Tm}_{\text {optimized }}=39^{\circ} \mathrm{C}\right.$ vs. $\left.\operatorname{Tm}_{\text {unoptimized }}=35.5^{\circ} \mathrm{C}\right)$ of $\mathrm{BAH}_{\mathrm{BAHD} 1}$ in thermal shift assays (TSA) (Fig. S2). ITC titration revealed a dissociation constant $\left(K_{\mathrm{D}}\right)$ of $15.9 \mu \mathrm{mol} / \mathrm{L}$ between $\mathrm{BAH}_{\mathrm{BAHD} 1}$ and $\mathrm{H}_{3}{ }_{15-42} \mathrm{~K} 27 \mathrm{me} 3$ peptide. By contrast, the binding affinity dropped to $2.6 \mathrm{mmol} / \mathrm{L}$ in the case of $\mathrm{H} 3_{1-15} \mathrm{~K} 9 \mathrm{me} 3$, and no bindings were observed for $\mathrm{H}_{31-10} \mathrm{R} 8 \mathrm{me} 2 \mathrm{~s}, \mathrm{H} 3_{1-15} \mathrm{~K} 14 \mathrm{ac}$, and $\mathrm{H} 3_{28-41} \mathrm{~K} 36 \mathrm{me} 3$ peptides (Fig. 1C, left), suggesting K27 sitespecificity. We next explored the methylation-state preference of $\mathrm{H} 3 \mathrm{~K} 27$ by $\mathrm{BAH}_{\mathrm{BAHD} 1}$. Following the loss of methyl groups, the binding affinity dropped 8-fold for H3K27me2 $\left(K_{\mathrm{D}}=116 \mu \mathrm{mol} / \mathrm{L}\right), 129$-fold for $\mathrm{H} 3 \mathrm{~K} 27 \mathrm{me} 1\left(K_{\mathrm{D}}=2.0 \mathrm{mmol} / \mathrm{L}\right)$ and lost completely for unmodified $\mathrm{H} 3 \mathrm{~K} 27$, suggesting $\mathrm{BAH}_{\mathrm{BAHD} 1}$ is a histone $\mathrm{H} 3 \mathrm{~K} 27$ trimethyllysine-specific reader (Fig. $1 \mathrm{C}$, right). Remarkably, phosphorylation of $\mathrm{H} 3 \mathrm{~S} 28$ (H3S28ph) dramatically reduced H3K27me3 binding by 42-fold $\left(K_{\mathrm{D}}=680 \mu \mathrm{mol} / \mathrm{L}\right)$, suggesting a "methyl-phos" binary

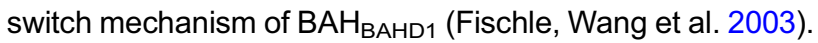



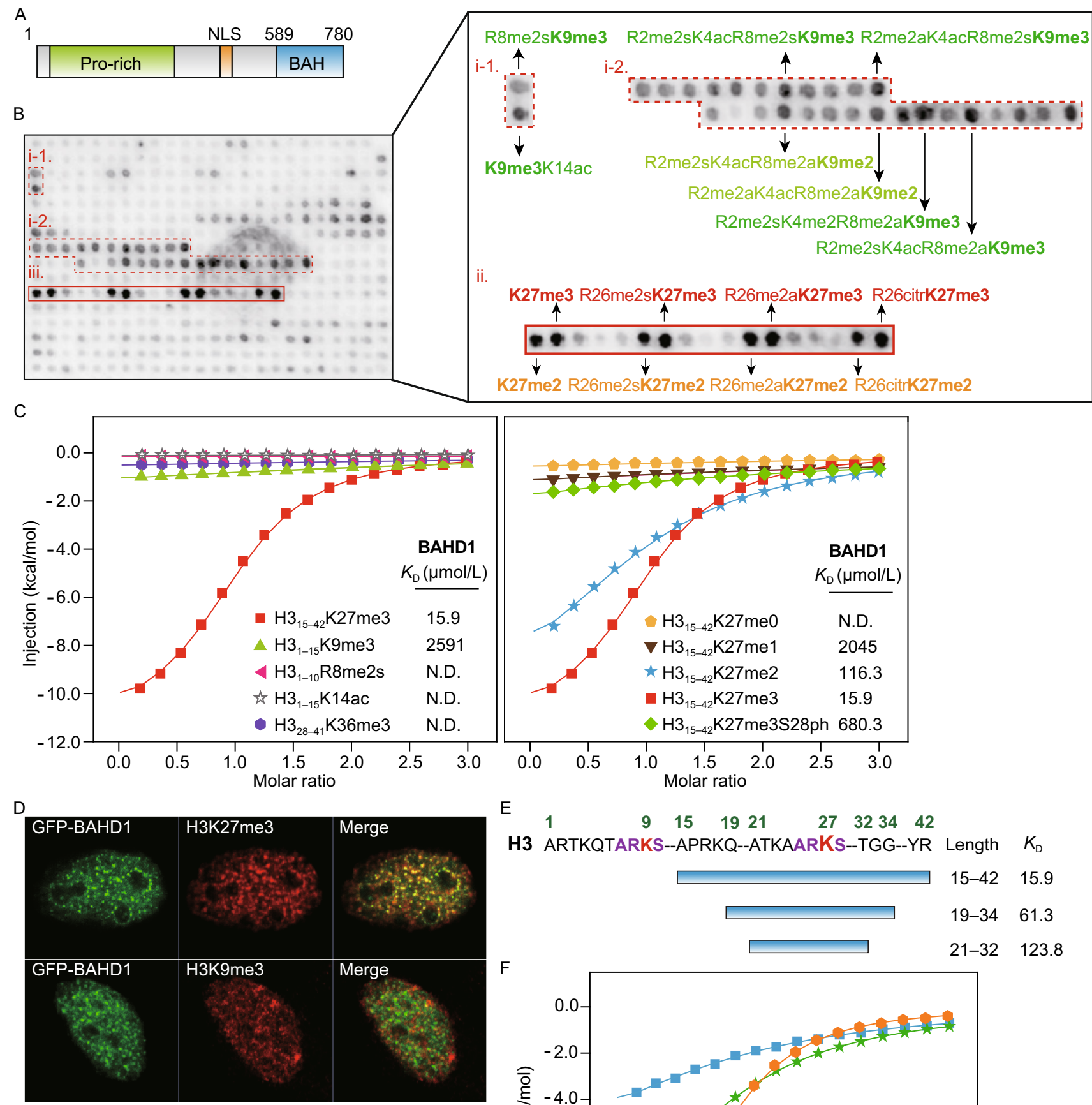

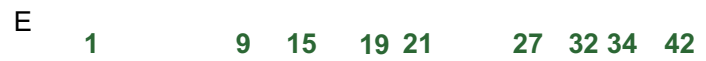

H3 ARTKQTARKS--APRKQ--ATKAARKS--TGG--YR Length $K_{D}$
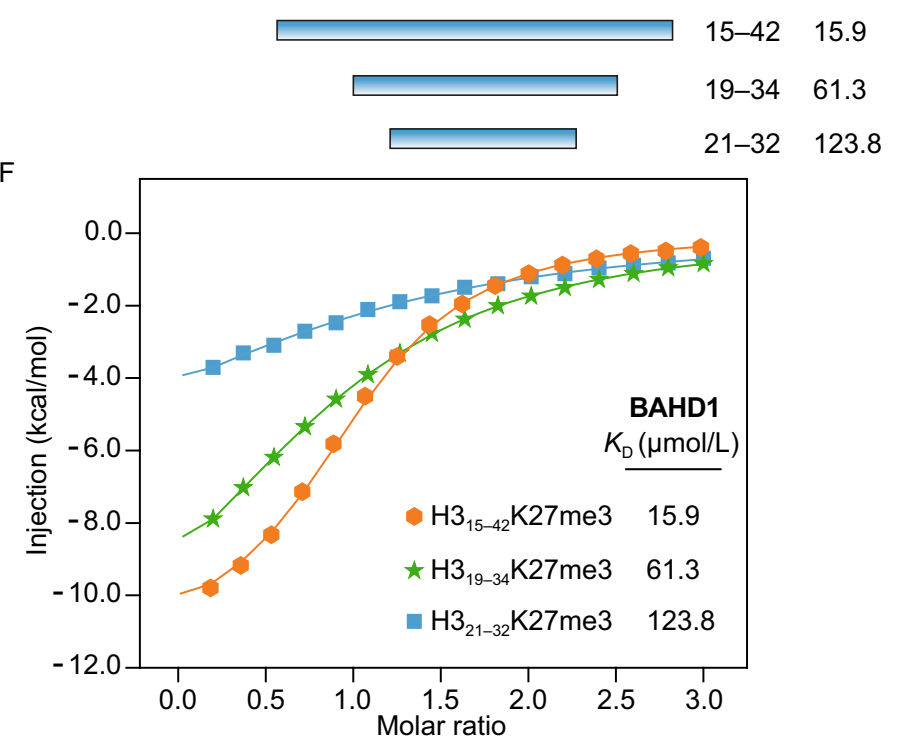
Figure 1. The BAHD1 BAH is an H3K27me3-binding domain. (A) Domain architecture of human BAHD1 protein. (B) A modified histone peptide array screen probed with GST-tagged $\mathrm{BAH}_{\mathrm{BAHD} 1}$ domain. Spots were detected by anti-GST antibody. Positive hits were labeled with red boxes and the corresponding peptides information was annotated on the right. $\mathrm{i}-1$ \& $\mathrm{i}-2$, peptides that contain $\mathrm{K} 9 \mathrm{me} 2 / \mathrm{me} 3$; ii, peptides that contain $\mathrm{K} 27 \mathrm{me} 2 / \mathrm{me} 3$. (C) Isothermal titration calorimetry (ITC) fitting curves of $\mathrm{BAH}_{\mathrm{BAHD} 1}$ domain with indicated histone peptides. $\mathrm{N}$. D., not detected. Peptide sequences and complete thermodynamic parameters were listed in Table S1. (D) Immunofluorescence of EGFP-BAHD1 (full length) transfected HeLa cells labeled with $\mathrm{H} 3 \mathrm{~K} 27 \mathrm{me} 3$ and $\mathrm{H} 3 \mathrm{~K} 9 \mathrm{me} 3$ antibodies. (E) ITC fitting curves of $\mathrm{BAH}_{\mathrm{BAHD} 1}$ domain titrated with different frames of the H3K27me3 peptides. (F) Diagram and sequence information of histone $\mathrm{H} 3 \mathrm{~K} 27 \mathrm{me} 3$ peptides used in the ITC titration.

Both $\mathrm{H} 3 \mathrm{~K} 9 \mathrm{me} 3$ and $\mathrm{H} 3 \mathrm{~K} 27 \mathrm{me} 3$ are hallmarks for heterochromatin and gene silencing (Kim and Kim 2012). To evaluate the in vivo functional distinction between the two marks in BAHD1 recruitment, we next performed co-localization analysis of BAHD1 with H3K9me3 or H3K27me3 in HeLa cells by immunofluorescence. As shown in Fig. 1D, ectopically expressed EGFP-BAHD1 overlapped nicely with the punctate staining pattern of $\mathrm{H} 3 \mathrm{~K} 27 \mathrm{me} 3$ as evidenced by the yellow appearance of merged signals. By contrast, little overlapping between EGFP-BAHD1 and H3K9me3 was observed. This result confirms the functional connection of BAHD1 with $\mathrm{H} 3 \mathrm{~K} 27 \mathrm{me} 3$ but not $\mathrm{H} 3 \mathrm{~K} 9 \mathrm{me} 3$ at cellular level. H3K9me3 and H3K27me3 share a common "ARKS" sequence motif (Fig. 1E). Additional ITC titrations using H3K27me3 peptides in shorter H3 frames of 19-34 and 21-32 revealed 3.9- and 7.8-fold binding reduction (Fig. 1F), suggesting that distal sequence motifs other than "ARKS" contribute to $\mathrm{H} 3 \mathrm{~K} 27 \mathrm{me} 3$ recognition and thus discriminate against $\mathrm{H} 3 \mathrm{~K} 9 \mathrm{me} 3$.

We next performed hydrogen exchange mass spectrometry (HXMS) to map the responsible regions of $B A H_{B A H D 1}$ for histone $\mathrm{H}_{3}{ }_{15-42} \mathrm{~K} 27 \mathrm{me} 3$ peptide binding (Wales and Engen 2006). Three peptide segments spanning "633-653", "666-691", and "674-698" of BAHD1 displayed obvious reduced exchange rates in the presence of the H3K27me3 peptide (Fig. 2A), suggesting their involvement in histone recognition. By contrast, other peptides show little or no change in deuterium uptake level upon binding to histone ligand. Structural modelling of $\mathrm{BAH}_{\mathrm{BAHD} 1}$ revealed that the three peptide segments cluster together to form a surface that contains an aromatic cage for methyllysine binding (Figs. 2B and S3). This aromatic cage is formed by $\mathrm{Y} 645, \mathrm{~W} 667$, and Y669, which are conserved among the BAH domains of mouse ORC1 and plant ZMET2 that are known to recognize H4K20me2 and H3K9me2, respectively (Fig. S4).

To test the importance of the aromatic residues in H3K27me3 readout by $B A H_{B A H D 1}$, we generated single point mutant of Y645A, W667A, Y669A, and performed ITC titration using $\mathrm{H}_{315-42} \mathrm{~K} 27$ me3 peptide. As expected, alanine mutation of the aromatic residues disrupted binding between $\mathrm{BAH}_{\mathrm{BAHD} 1}$ and H3K27me3 peptide (Fig. 2C), supporting a critical role of the aromatic cage in methyllysine recognition. The importance of these aromatic residues was further confirmed by immunofluorescence analysis in HeLa cells. As shown in Fig. 2D and quantification in Fig. 2E, Y645A, W667A, and Y669A mutant EGFP-BAHD1 failed to co-localize with $\mathrm{H} 3 \mathrm{~K} 27 \mathrm{me} 3$ compared with the wild type protein, thus supporting the functional importance of the aromatic cage for heterochromatin targeting by BAHD1 in vivo.

In sum, combining peptide array screen, quantitative binding, hydrogen exchange MS, and cellular co-localization studies, we established that BAHD1 BAH domain is an H3K27me3-specific reader that discriminates against H3K9me3. H3K27me3 often marks facultative heterochromatin with important functional implications in gene regulation, cell differentiation and development (Gaydos, Wang et al. 2014). By contrast, histone H3K9me3 represents a hallmark for constitutive heterochromatin and can be recognized by effector proteins such as HP1 to maintain structurally condensed chromatin conformation. Our quantitative ITC assays revealed that the binding affinity of $\mathrm{BAH}_{\mathrm{BAHD} 1}$ to H3K27me3 ( $\left.K_{\mathrm{D}}=15.9 \mu \mathrm{mol} / \mathrm{L}\right)$ is more than two orders of magnitude stronger than $\mathrm{H} 3 \mathrm{~K} 9 \mathrm{me} 3$ $\left(K_{\mathrm{D}}=2.6 \mathrm{mmol} / \mathrm{L}\right)$. This recognition preference suggests that distal sequences flanking the K9/K27 consensus "ARKS" motif contribute to $\mathrm{H} 3 \mathrm{~K} 27 \mathrm{me} 3$ recognition. In support, an optimal binding between $\mathrm{H} 3 \mathrm{~K} 27 \mathrm{me} 3$ and $\mathrm{BAH}_{\mathrm{BAHD} 1}$ is achieved in a long frame of 15-42 but not in shorter segments of 19-34 or 21-32. Exact molecular basis underlying $\mathrm{H} 3$ distal sequence recognition calls for complex structure determination in the future. Utilizing hydrogen exchange MS, we were able to map key segments within $\mathrm{BAH}_{\mathrm{BAHD} 1}$ that are responsible for $\mathrm{H} 3 \mathrm{~K} 27 \mathrm{me} 3$ binding. Notably, spatial arrangement of these key segments in modelled $\mathrm{BAH}_{\mathrm{BAHD} 1}$ structure underscored the role of an aromatic cage consisting of $Y 645$, W667, and Y669 for H3K27me3 readout, a mechanism conserved in many other methyllysine readers (Patel and Wang 2013). Subsequent ITC titration and immunofluorescence studies comparing wild type and mutant BAH $\mathrm{BAHD}_{\mathrm{B} 1}$ further confirmed the importance of the aromatic cage in histone H3K27me3 readout both in vitro and in vivo.

Previously reported H3K27me3 readers include EED WD40 repeats of the PRC2 complex (Margueron, Justin et al. 2009) and Pc family chromodomain of the PRC1 complex (Kaustov, Ouyang et al. 2011). Here we characterized human BAHD1 BAH domain as a third class of histone H3K27me3 reader that functions to facilitate BAHD1 heterochromatin targeting and subsequent gene silencing. Moreover, our work revealed that the binding of $\mathrm{BAH}_{\mathrm{BAHD} 1}$ to $\mathrm{H} 3 \mathrm{~K} 27 \mathrm{me} 3$ was markedly disrupted by adjacent H3S28 phosphorylation-a hallmark of the transcriptional response to stress signaling (Sawicka, Hartl et al. 2014). BAHD1 is overexpressed in peripheral blood mononuclear cells and pancreas, and excels critical function to maintain a repressive state of interferon- 

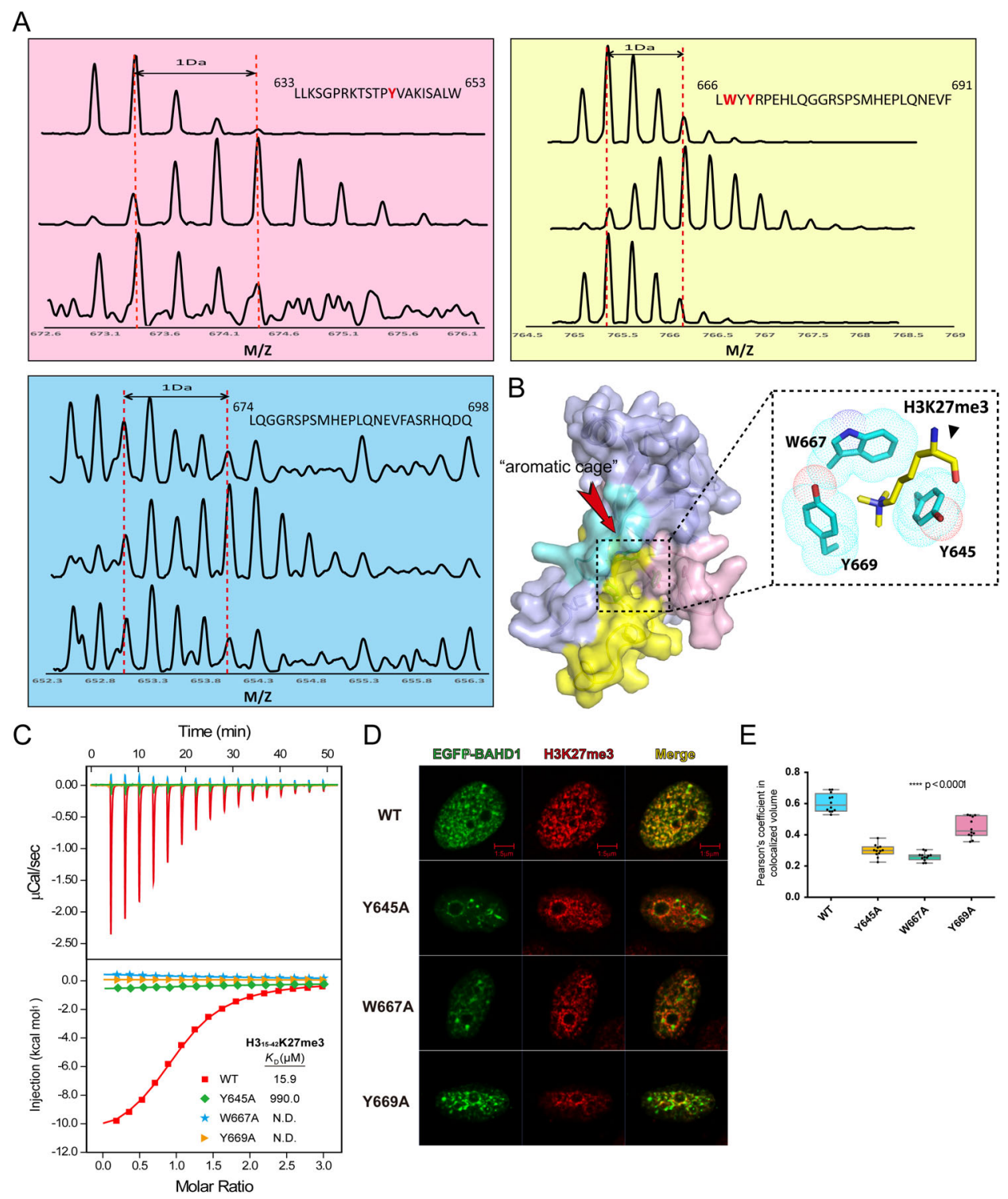

E

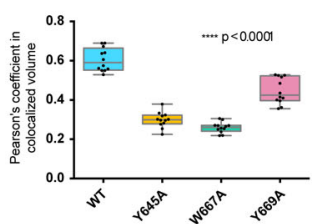

Figure 2. An aromatic cage is required for $H 3 K 27$ me3 recognition by $B A H_{B A H D 1}$ domain. (A) Hydrogen exchange MS (HXMS) analysis of $\mathrm{BAH}_{\mathrm{BAHD} 1}-\mathrm{H} 3 \mathrm{~K} 27 \mathrm{me} 3$ complexion. Representative deuterium exchange mass spectra of $\mathrm{BAH} \mathrm{H}_{\mathrm{BAH} 1}$ peptide fragments. Sections of $\mathrm{BAH}_{\mathrm{BAHD} 1}$ peptides from 633-653 are shown in pink; 666-691 in yellow and 674-698 in blue (In each section, top: undeuterated sample; middle: $\mathrm{BAH}_{\mathrm{BAHD} 1}$ only peptides after $10 \mathrm{~min}$ in deuterated buffer; down: $\mathrm{BAH} \mathrm{BAHD}_{1}$ with $\mathrm{H} 3 \mathrm{~K} 27 \mathrm{me} 3$ after 10 min in deuterated buffer). (B) $\mathrm{H} 3 \mathrm{~K} 27$ me3 binding region mapping of $\mathrm{BAH}_{\mathrm{BAHD} 1}$ based on the HX MS data. The structure model of $\mathrm{BAH}_{\mathrm{BAHD} 1}$ was obtained by homologous modelling. $\mathrm{BAH} \mathrm{HAHD}_{\mathrm{B} 1}$ structure is shown in surface view with the corresponding $\mathrm{H} 3 \mathrm{~K} 27 \mathrm{me} 3$ binding region color coded pink, yellow, and cyan corresponding to panel (A). Arrow highlights the aromatic cage formed at the center of $\mathrm{BAH} \mathrm{BAHD}_{\mathrm{B} 1}$. A close-up view of the aromatic cage with a modelled H3K27me3 ligand is shown top-right. (C) ITC fitting curves of histone $\mathrm{H}_{15-42} \mathrm{~K} 27$ me3 peptide with wild type (WT) and mutant BAH $\mathrm{BAHD}_{1}$ (Y645A, W667A, and Y669A). (D) Immunofluorescence of EGFP-BAHD1 and mutants transfected HeLa cells labeled with $\mathrm{H} 3 \mathrm{~K} 27 \mathrm{me} 3$ antibody. Scale bar represents $5 \mu \mathrm{m}$. (E) Quantification of EGFP-BAHD1 and mutants signals co-localized with H3K27me3. Counts are based on 12 interphase cells in individual clones and the Pearson's coefficient of each cell was listed in Table S2.

stimulated genes and insulin-like growth factors (Bierne, Tham et al. 2009, Lebreton, Lakisic et al. 2011). Given the critical role of H3S28ph in signal-induced transcription, the observed "binary switch" between H3K27me3 and H3S28ph may serve as an important mechanism to derepress BAHD1mediated gene silencing. 


\section{FOOTNOTES}

We'd like to acknowledge the Center of Biomedical Analysis in Tsinghua University for assistance in using Zeiss LSM 710 microscope and Imaris software. This work was supported by grants from the National Basic Research Program (973 Program) (No. 2015CB910503), the Tsinghua University Initiative Scientific Research Program and the National Natural Science Foundation of China (Grant No. 91519304) to H.L.

All authors declare that they have no conflict of interest. This article does not contain any studies with human or animal subjects performed by the any of the authors.

Dan Zhao ${ }^{1,2}$, Xiaojie Zhang ${ }^{2}$, Haipeng Guan ${ }^{2}$, Xiaozhe Xiong ${ }^{3}$, Xiaomeng $\mathrm{Shi}^{3}$, Haiteng Deng ${ }^{3}$, Haitao $\mathrm{Li}^{2,4 \bowtie}$

${ }^{1}$ College of Life Sciences, Peking University, Beijing 100871, China

${ }^{2}$ MOE Key Laboratory of Protein Sciences, Beijing Advanced Innovation Center for Structural Biology, Department of Basic Medical Sciences, School of Medicine, Tsinghua University, Beijing 100084, China

${ }^{3}$ Center for Biomedical Analysis, School of Medicine, Tsinghua University, Beijing 100084, China

${ }^{4}$ Collaborative Innovation Center for Biotherapy, West China Hospital, Sichuan University, Chengdu 610041, China

$\bowtie$ Correspondence: Iht@tsinghua.edu.cn (H. Li)

\section{OPEN ACCESS}

This article is distributed under the terms of the Creative Commons Attribution 4.0 International License (http://creativecommons.org/ licenses/by/4.0/), which permits unrestricted use, distribution, and reproduction in any medium, provided you give appropriate credit to the original author(s) and the source, provide a link to the Creative Commons license, and indicate if changes were made.

\section{REFERENCES}

Bierne H, Tham TN, Batsche E, Dumay A, Leguillou M, KerneisGolsteyn S, Regnault B, Seeler JS, Muchardt C, Feunteun J, Cossart P (2009) Human BAHD1 promotes heterochromatic gene silencing. Proc Natl Acad Sci USA 106(33):13826-13831

Chambers AL, Pearl LH, Oliver AW, Downs JA (2013) The BAH domain of Rsc2 is a histone $\mathrm{H} 3$ binding domain. Nucleic Acids Res 41(19):9168-9182
Du J, Johnson LM, Jacobsen SE, Patel DJ (2015) DNA methylation pathways and their crosstalk with histone methylation. Nat Rev Mol Cell Biol 16(9):519-532

Fischle W, Wang YM, Allis CD (2003) Binary switches and modification cassettes in histone biology and beyond. Nature 425(6957):475-479

Gaydos LJ, Wang W, Strome S (2014) Gene repression. H3K27me and PRC2 transmit a memory of repression across generations and during development. Science 345(6203):1515-1518

Jenuwein T, Allis CD (2001) Translating the histone code. Science 293(5532):1074-1080

Kaustov L, Ouyang H, Amaya M, Lemak A, Nady N, Duan S, Wasney GA, Li Z, Vedadi M, Schapira M, Min J, Arrowsmith $\mathrm{CH}$ (2011) Recognition and specificity determinants of the human cbx chromodomains. J Biol Chem 286(1):521-529

Kim J, Kim H (2012) Recruitment and biological consequences of histone modification of $\mathrm{H} 3 \mathrm{~K} 27 \mathrm{me} 3$ and $\mathrm{H} 3 \mathrm{~K} 9 \mathrm{me} 3$. ILAR J 53(3-4):232-239

Kuo AJ, Song J, Cheung P, Ishibe-Murakami S, Yamazoe S, Chen JK, Patel DJ, Gozani O (2012) The BAH domain of ORC1 links H4K20me2 to DNA replication licensing and Meier-Gorlin syndrome. Nature 484(7392):115-119

Lebreton A, Lakisic G, Job V, Fritsch L, Tham TN, Camejo A, Mattei PJ, Regnault B, Nahori MA, Cabanes D, Gautreau A, Ait-Si-Ali S, Dessen A, Cossart P, Bierne H (2011) A bacterial protein targets the BAHD1 chromatin complex to stimulate type III interferon response. Science 331(6022):1319-1321

Margueron R, Justin N, Ohno K, Sharpe ML, Son J, Drury WJ 3rd, Voigt P, Martin SR, Taylor WR, De Marco V, Pirrotta V, Reinberg D, Gamblin SJ (2009) Role of the polycomb protein EED in the propagation of repressive histone marks. Nature 461(7265): 762-767

Patel DJ, Wang Z (2013) Readout of epigenetic modifications. Annu Rev Biochem 82:81-118

Sawicka A, Hartl D, Goiser M, Pusch O, Stocsits RR, Tamir IM, Mechtler K, Seiser C (2014) H3S28 phosphorylation is a hallmark of the transcriptional response to cellular stress. Genome Res 24 (11):1808-1820

Wales TE, Engen JR (2006) Hydrogen exchange mass spectrometry for the analysis of protein dynamics. Mass Spectrom Rev 25 (1):158-170

Yang N, Xu RM (2013) Structure and function of the BAH domain in chromatin biology. Crit Rev Biochem Mol Biol 48(3):211-221

Electronic supplementary material The online version of this article (doi:10.1007/s13238-016-0243-z) contains supplementary material, which is available to authorized users. 